\title{
Ser indigena en una cuadrilla de blancos. Migración y trabajo agricola racializado en la era de la globalización ${ }^{1}$
}

\author{
Rafael Alonso Hernández López ${ }^{2}$ \\ Centro de Investigaciones y Estudios Superiores en Antropología \\ Social, México D.F., México ${ }^{3}$ \\ loncho_hdz@hotmail.com \\ Recibido: 23 de julio de 2013 \\ Aceptado: 26 de septiembre de 2013
}

Artículo de reflexión. Forma parte de la tesis doctoral en proceso de construcción: "Migración interna y racismo: jornaleros agrícolas en Los Altos de Jalisco" que se efectúa con financiamiento del Consejo Nacional de Ciencia y Tecnologia (Conacyt) en su programa de Becas para estudios de posgrado.

2 Licenciado en Filosofia por el Instituto de Formación Filosófica Intercongregacional de México. Magíster en Ciencias Sociales y Humanísticas del Centro de Estudios Superiores de México y Centroamérica de la Universidad de Ciencias y Artes de Chiapas.

3 Estudiante doctoral en Ciencias Sociales del Centro de Investigaciones y Estudios Superiores en Antropología Social, unidad Occidente. 


\title{
Ser indigena en una cuadrilla de blancos. Migración y trabajo agricola racializado en la era de la globalización
}

\section{Resumen}

La finalidad de la presente reflexión es analizar las relaciones étnico-raciales que se generan en espacios laborales agricolas y que decantan en prácticas racistas propiciadas por las migraciones de población indigena de Chiapas a la zona tequilera de los Altos de Jalisco en México, específicamente al municipio de Arandas. Dichas relaciones se vienen dando desde finales del siglo pasado a raíz de la creciente expansión de la agroindustria del tequila. Es de interés particular abordar cuestiones que versan sobre las relaciones laborales y sociales en las que los migrantes se insertan en el medio al que llegan, porque estas relaciones se sustentan en una apreciación negativa de la diferencia. Esta actitud lleva a los oriundos de Jalisco a discriminar, segregar, marginar y explotar, no solo al que es extraño en tanto extranjero (aun en el mismo país), sino a quien, por su condición indígena, es posicionado en un estrato inferior, además de que su fenotipo dista mucho del alteño idealizado, el de tipo caucásico, católico, ranchero.

Palabras clave: Migración indigena, Racismo, Etnicidad, Altos de Jalisco, Relaciones laborales, Identidad, Inferiorización.

Palabras clave descriptores: Indígenas de México-Aspectos socioeconómicos, Racismo, Etnicidad, Relaciones laborales, Identidad nacional, Migración interna-Altos de Jalisco (México)

\section{Being an Indian on a White gang. Migration and Racialized Agricultural Labor in the Era of Globalization.}

\begin{abstract}
The purpose of this reflection is to analyze the ethnic-racial relations generated in agricultural workplaces that tilt in racist practices caused by the indigenous population migrations from the area of Chiapas to the land of tequilain Altos de Jalisco located in Mexico, specifically the municipality of Arandas. Such relationships have been evolving since the end of the last century as a result of the increasing expansion of the tequila agro-industry. It is of particular interest to address issues that deal with labor and social relations in the environments migrants arrive, because these relationships are based on a negative appreciation of the difference. This attitude leads the native people of Jalisco to discriminate, segregate, marginalize and exploit, not only strangers or foreigners (even in the same country), but also who, by his indigenous status, is positioned in a lower stratum and whose phenotype is far from the idealized Altos del Jalisco native: the Caucasian type, Catholic, rancher.

Keywords: Indigenous Migration, Racism, Ethnicity, Altos de Jalisco, Labor Relations, Identity, Inferiority.
\end{abstract}

Key words plus: Indians of Mexico, Socioeconomic Aspects, Racism, Ethnicity, Labor Relations, National Identity, International Migration Altos de Jalisco (Mexico)

\section{Ser indigena em uma gangue de brancos. Migração e trabalho agricola racializado na era da globalização.}

\section{Resumo}

O objetivo desta reflexão é analisar as relações étnico-raciais geradas em espaços laborais agrícolas e decantadas em práticas racistas propiciadas pelas migrações dos povos indígenas de Chiapas para a zona tequileira dos Altos de Jalisco no México, especificamente ao município de Arandas. Tais relações têm vindo evoluindo desde finais do século passado como resultado da crescente expansão da agroindústria da tequila. De interesse particular é abordar questões que têm a ver com as relações laborais e sociais nas que os migrantes inserem-se no meio onde eles chegarem, porque estas relações são baseadas em avaliações negativas da diferença. Essa atitude leva os oriundos de Jalisco para discriminar, segregar, marginar e explorar, não apenas ao estrangeiro por esquisito (ainda no próprio país), senão quem, por sua condição indígena, é colocado em um estrato inferior, além de o seu fenótipo distar bastante do altenho idealizado, o de tipo caucasiano, católico, rancheiro.

Palavras-chave: Migração indígena, Racismo, Etnicidade, Altos de Jalisco, Relações laborais, Identidade, Inferiorização.

Palavras-chave descritores: Indígena do México, Aspectos sócio-econômicos, Racismo, Etnicidade, Relações de trabalho, Identidade nacional, Migração internacional-Altos de Jalisco (México) 


\section{Introducción}

En el México moderno, la región de Los Altos de Jalisco se configura como un espacio en el que cristalizan tres imaginarios representativos de la llamada identidad nacional: la figura del charro, el tequila y la religión. El primero, enmarcado en un estereotipo de género que se supone lo define como valiente, dicharachero, cercano al campo, mujeriego, tenaz, intrépido; muy vinculado también a una concepción imaginaria de un fenotipo ideal, asumido como un privilegio y un honor, en el que se sustenta la apreciación estética de sus contrapartes, pues se supone que emana de una herencia colonial española manifestada en la blanquitud. El segundo imaginario es una bebida que gracias a la globalización, se ha configurado como referente nacional ante los ojos del mundo. Su botella contiene, no solo un licor, sino la vida de un pueblo, una región, una Nación. El tercer imaginario nutre, da sentido y orientación a la vida de miles de familias. Es una institución fundamental en la valoración de actitudes, dota sentido y orientación a muchas de las prácticas que los alteños realizan cotidianamente, sean estas sociales, económicas, políticas o culturales.

Estas tres notas referentes de la identidad forman un círculo vicioso en donde lo considerado nacional da vida y sustento a lo alteño, y a su vez, a lo nacional. Se trata de una dinámica compleja en la que interviene la historia nacional pre-colonial y colonial que toma vida en una región fundada estratégicamente para atender necesidades de sustento y de seguridad del Reino de la Nueva Galicia en el Occidente de México, situación que con el pasar de los siglos fue configurando la manera de asumirse y pensarse de los pueblos que conforman dicha región geográfica e identitaria.

Es en este escenario en el que desde hace casi diez décadas se vienen construyendo historias migratorias hacia los Estados Unidos, convirtiendo a la región en uno de los bastiones históricos de la migración internacional mexicana, a pesar incluso, del impacto de la agroindustria del tequila y sus transformaciones a partir de 1994. Dichas transformaciones han impactado a la región y han desencadenado, entre otras situaciones, el inédito proceso de migración interna de jornaleros indígenas provenientes del sureste mexicano hacia Los Altos de Jalisco.

Un contingente importante de mano de obra indígena proveniente de Chiapas fue llevada a los campos agrícolas de Los Altos de Jalisco. Su llegada provocó inquietud, insatisfacción y cierto recelo en la población 
local, por motivos de un supuesto desplazamiento en lo laboral, pero más bien, porque los indígenas son la corporalización de aquello que en el imaginario regional y nacional representa incivilización, pasividad, precariedad e inferioridad. Son aquello que no se desea y por esto fueron etiquetados étnica y racialmente bajo la categoria chiapas sinónimo de lo que es considerado como indígena por los alteños, pues se trata de ser ese otro no alteño, que posibilita y justifica la explotación, segregación y discriminación.

Con tales presupuestos, la presente reflexión pretende evidenciar cómo en el trabajo agrícola se conjugan imaginarios nacionales y regionales que siguen dando muestra del posicionamiento en escala superior del mestizo frente al indigena, históricamente considerado como inferior. Ello, en el contexto de producción de una bebida global como el tequila. La cuestión tiene que ver con una identidad que se refuerza y saca a relucir sus límites étnicos ante la aparición de la diferencia, con la peculiaridad de que ya no es el alteño quien se ve confrontado al salir de su territorio en el contexto de sus históricas migraciones a Estados Unidos, sino que es confrontado en su propio territorio, con la llegada de personas consideradas ajenas al mismo. Es así que también se propone analizar el uso y función de la etnicidad, raza, clase y cultura en las relaciones laborales entre indigenas migrantes y alteños en Jalisco.

Lo aquí expuesto forma parte de las investigaciones preliminares en las que se enmarca mi tesis doctoral que sigue una apuesta metodológica cualitativa sustentada fundamentalmente en el trabajo de campo in situ durante ocho meses y la realización de entrevistas a la población alteña e indígena en Los Altos de Jalisco, específicamente en el municipio alteño de Arandas.

\section{Nuevos fenómenos para una nueva sociedad: migración indigena a Los Altos de Jalisco}

La región de Los Altos de Jalisco se ha configurado como un espacio en el que convergen definiciones históricas de tipo político, económico, cultural, ambiental y religioso que hacen de la misma, una región dificil de delimitar en cuanto a extensión territorial. No hay unanimidad con respecto a cuáles municipios pertenecen a cada una de las definiciones antes mencionadas, sin embargo se sabe que es un campo que abarca entre 19 y 26 municipios de Jalisco, en donde, "lo común es que lo alteño gravita 
en medio de un campo de fuerza formado por las principales ciudades del centro occidente: Guadalajara, Aguascalientes, León, San Luis Potosí...” (Gilabert y Camarena, 2004, p. 33). Este territorio tenía por finalidad servir de frontera entre Mesoamérica y Aridoamérica, así como de articular la producción agro-ganadera con las zonas mineras (Fábregas, 1986, p. 101).

Ante la imposibilidad de dominar militarmente la región y asegurar el trasiego de mercancías, los conquistadores hicieron frente a la resistencia chichimeca recurriendo a la "estrategia militar de etnocidio, para lograrlo, trasladaron a campesinos de diferentes partes de Castilla, a poblar Los Altos de Jalisco, asentándose con patrones de propiedad privada y con una ideología católica fundamentalista" (López, 1999, p. 39). Dicha estrategia de cederles tierra en propiedad permitía una ocupación permanente del territorio, con lo cual a su vez se garantizaba la producción, comercialización y protección de granos, carnes y mercancías.

Desde el establecimiento de los pobladores de la corona española hasta el siglo XIX, la cría de ganado se consolida como la principal actividad económica de la región, de la cual se aprovechaba carne, grasa, piel, lácteos y demás para abastecer a las poblaciones establecidas en las minas de Zacatecas y Guanajuato (Hernández, 2005, p. 1). Esa situación posibilitó además que se fuera definiendo el imaginario identitario de la región en torno al rancho, entendido como un terreno no muy extenso, más bien de pequeña o mediana extensión, que a la par de un conjunto de prácticas y valores, permiten entender el surgimiento y consolidación de una cultura ranchera (Gilabert y Camarena, 2004, p. 146). En la segunda mitad del siglo XX, la actividad ganadera ya consolidada en la región facilitó la creación de una cuenca lechera que abastecía de productos lácteos a la zona centro-occidente del país. Ello por supuesto supuso ajustes en la organización social, económica y política de la región. "El Estado y la industria se constituyeron como nuevos ejes centrales, vectores de la auto-organización sociocultural y de las relaciones sociales, generando nuevos procesos de dominación" (López, 1999, p. 17).

Para la época mencionada, Los Altos de Jalisco eran ya un bastión importante de migración mexicana a los Estados Unidos, cuyos migrantes en su mayoria, eran enrolados por el programa bracero, en el que destaca la inserción de jornaleros jaliscienses (Durand, 2007). Esta experiencia va a servir como mecanismo de atracción para muchos campesinos jaliscienses con quienes, al paso de los años, se consolidan 
varias redes migratorias que terminan por establecer una cultura migratoria en la región.

A la par de las actividades ganaderas que comenzaron a ser cada vez más rentables con la apertura comercial al final de la década de 1980 y durante toda la década de 1990, se gestaron transformaciones industriales de gran relevancia en la región y apareció en escena un actor que se había mantenido relativamente en los márgenes de la vida comercial de la región: el tequila. No obstante estas transformaciones o quizá más bien en concordancia con las mismas, la unidad productiva por excelencia continuó siendo el rancho, de tal suerte que las actividades, ahora empresariales, tienen como su núcleo la actividad agrícola.

Más allá de ser una región eminentemente geográfica, Los Altos de Jalisco se ha consolidado como una región identitaria en la que se preservan y actualizan valores propios de una sociedad peculiar en el México moderno. Si bien es cierto que la identidad no es una camisa de fuerza en la que se constriñen anhelos, ilusiones y estilos de vida, desde esta perspectiva de estudio, la identidad es una directriz para nada coercitiva, que va guiando, sugiriendo, abriendo camino en la cosmovisión, forma de concebirse y de accionar en la vida de las personas. "La identidad es una construcción social originada en representaciones"(Carrillo y Salgado, 2002, p. 49), por lo cual es indispensable pensarla en el marco de un contexto social en el que intervienen grupos sociales diversos que recurren a un proceso de identificación y diferenciación de las actitudes, aptitudes, habilidades y costumbres que permiten demarcar lo propio de lo considerado como ajeno.

El caso de los alteños de Jalisco destaca por la vigencia de algo que se considera una impronta, construida, reforzada y actualizada con el pasar de los años, pero también revitalizada por una dinámica ideológica nacional en la que se encauzan sus argumentos. Cobra vital importancia para los alteños el mito fundacional de la identidad nacional sustentado en la idea de que los grupos que habitan un espacio fisico determinado:

(...) compartirian consecuentemente, intereses, derechos y símbolos que los convertirian en una comunidad de pertenencia (...) la identidad nacional se construyó sobre la base de una idea de Nación que aspiraba a integrar las diferencias culturales contenidas en un territorio específico, estableciendo una identidad y una cultura común-que tenía 
como propósito superar la existencia de diversas identidades étnicas-, en las que todos los hombres observaran un mismo referente político, social, económico y cultural centrado en el Estado Moderno. (Delgado, 2007, pp. 17-18)

La construcción de la identidad alteña está estrechamente vinculada con el constructo identitario nacional, traslapándose constantemente, al grado tal que los más importantes símbolos de la mexicanidad se encarnan o se crean en el contexto regional alteño: el charro, el mariachi, el tequila, la religiosidad. Todos ellos forman parte de lo que aquí se denominan representaciones identitarias, es decir, la materialización de los ideales, anhelos e ideologias de una supuesta identidad homogénea: blanco-mestiza, creyente y con fuertes relaciones de parentesco.

Tal como se mencionó antes, la vida de la región se configuró en torno a lo rural, a lo campestre, al rancho. Había un vínculo de inmediatez con la vida campesina. El campo representaba para la mayoría de la población su fuente primaria de subsistencia. Si bien, la migración a los Estados Unidos y la de los pocos que tenían la posibilidad de migrar a las ciudades para estudiar, principalmente Guadalajara, capital del estado de Jalisco, proveía al municipio de atisbos de urbanidad, cosmopolitismo y desarrollo, aquellos insumos se veían como lejanos para la población local.

Fue el auge del tequila el que dio inicio a la transición hacia una sociedad de tipo moderno, en el sentido de dotar al municipio de bienes y servicios, dinámicas que influyeron en el despunte de una transformación social, cultural, religiosa, urbanística y ecológica del municipio, que se encuentra en ciernes. En esta fase de transición el campo no ha dejado de ser un referente de gran importancia. Lo que cambió fue la manera de acercarse y relacionarse con él. La configuración de un reparto de tierras vía herencia familiar, que ha hecho de la pequeña propiedad una nota constitutiva de la región, siguió y sigue operando como proceso facilitador de estas maneras de relacionarse con el campo. Este proceso contribuyó a consolidar la identidad ranchera de la región.

Los alteños, hombres y mujeres, mantienen un vínculo directo con la vida del campo, ya sea como campesinos, es decir, sujetos rurales que viven del y para el campo, o como personas campestres que siguen valorando el lugar del campo y de lo natural en su vida. Para ellos el campo pasa a ser entonces un elemento accesorio, estético, de disfrute 
y goce más que una forma de vida. Dicha relación con el campo, construyó a su vez una idea de género que ha servido para reforzar los estereotipos de identidad de los alteños.

El tradicional charro, héroe petrificado por el cine de oro mexicano, ha alcanzado un referente ineludible en Los Altos de Jalisco: el valentón, dicharachero, macho, trabajador. En contraparte está la mujer, caracterizada en base a sus atributos físicos, como referente de belleza nacional (alta, blanca, de ojos claros, referentes de origen criollo), pero también como depositaria de los valores religiosos imperantes en la zona: noble, sumisa, comprometida y virgen. Ambas figuras, más que desaparecer, se recrean y actualizan con los nuevos influjos que la globalización está suministrando al municipio de Arandas y sus habitantes.

Las nuevas lógicas de vida no solo han trastocado la relación con el campo, sino directamente con el trabajo, otro de los referentes regionales. En la actualidad la gente se percibe como muy trabajadora, en el sentido no de despliegue de capacidades físicas, sino más bien de audacia, destreza, habilidad para crear negocios, siendo los más destacados los que tienen que ver con el ramo agrícola, ganadero y comercial, de manera más reciente el industrial, vía la producción de tequila.

Estas maneras de concebirse y ser concebido en la sociedad alteña han moldeado un conjunto de prácticas y hábitos que configuran el complejo mundo de las relaciones sociales y laborales entre los pobladores alteños, así como entre las personas que literal o metafóricamente no pertenecen a él. Se ha hablado aquí de un colectivo con referentes de identificación fuertes con una antesala histórica que sigue viva, factores que en su conjunto ponen las condiciones para explicitar las formas de relacionarse con los otros, especialmente aquellos que son radicalmente diferentes, que ni siquiera aparecen en el imaginario construido en la región.

Las transformaciones de la industria del tequila en la región alteña han ido de la mano de un proceso de globalización de tipo empresarial, económico y transnacional -que implica la entrada en vigor de nuevas lógicas de organización del mercado de trabajo-, y en la comercialización de la bebida, que se hacen manifiestas por ejemplo, en las medidas de contratación que cada vez son más selectivas, despersonalizadas y herméticas, así como en la creación de instancias y mecanismos para la protección y difusión de la bebida representativa de lo nacional, tanto dentro como fuera del país, tal como lo evidencia 
la existencia de Consejo Regulador del Tequila (En base a notas de diario de campo 2012), (Hernández, 2005).

Toda la reestructuración de la agroindustria del tequila, indudablemente respondió a factores productivos regionales e incluso nacionales pero también al anclaje a un mercado de escala mundial que implicó la gran comercialización y el posicionamiento del tequila fuera de las fronteras nacionales y de igual manera, el establecimiento de empresas transnacionales para la producción y comercialización de esta espirituosa bebida.

Esta modernización agrícola no se tradujo en mejores condiciones laborales para quienes desde sus inicios formaron parte de la actividad tequilera, sino todo lo contrario. Los trabajadores que guardaban una cierta tradición en el manejo del mezcal y producción del tequila, no solo fueron dejados de lado sino que además, ellos mismos fueron los que garantizaron, mediante su explotación, ese paso de la producción a pequeña escala, con métodos tradicionales, a otra nueva fincada en la confianza obtenida en el conocimiento de las nuevas ciencias y su aplicación por medio de la tecnología.

La ahora tan tradicional bebida, se ha convertido en uno de los aparentes símbolos de lo que es México o mejor dicho lo que es lo mexicano. Esta situación ha creado una especie de arraigo y la consiguiente apropiación de la riqueza simbólica de dicho producto. De ahí que un supuesto buen arandense es aquel que sabe hacer del tequila un fiel compañero, pues tomarlo ${ }^{4}$ es la expresión más fidedigna de la reciproca pertenencia al tequila, a la región y al municipio.

Para entender la situación de la reconversión productiva e institucional en torno al tequila, es pertinente aclarar que hasta la década de 1980 la plantación de mezcal, otrora agave, era una actividad complementaria en la economía familiar, dado que las labores entonces practicadas por los campesinos en torno a dicha planta eran prácticamente pocas y sin especialización alguna, por tanto, las actividades realizadas no requerian división del trabajo como la de los otros cultivos. Los trabajadores del campo eran definidos como agricultores, medieros, peones; máxime si se tiene en cuenta que al ser el tequila un producto de consumo regional más que nacional, la oferta rebasaba la demanda y no era necesario producir todo el año, lo cual también interrumpía las actividades del campo.

\footnotetext{
4 Beber, ingerir.
} 
Con la expansión comercial del tequila se desencadenó un fenómeno inédito en la región productora de los Altos de Jalisco: la migración de jornaleros indígenas chiapanecos a los campos agaveros. No se trata ya de migración a Estados Unidos, a centros urbanos o a zonas rurales históricamente identificadas, ni tampoco para trabajar en campos de frutas, hortalizas, flores, etcétera, sino más bien de nuevas lógicas de migración, mercado y de trabajo en una sociedad que se encuentra en un contexto de transformación constante a raíz de las dinámicas de producción tequilera. En el espacio laboral de la producción tequilera se configura el escenario donde se tensiona la identidad étnica alteña con su contraparte indígena.

\section{Etnicidad, clase y racismo, paradojas del trabajo agrícola alteño en la globalización}

El trabajo agrícola es un elemento importante dentro de la identidad alteña, pero también en términos económicos se ha vuelto un referente para la región y la Nación. Con el boom tequilero se incrementaron, diversificaron y especializaron los tipos de tareas que se realizan en el campo, generando una organización del trabajo establecida, ya no solo por jornada o por hora, sino por trabajo específico. Este es el caso de jornaleros alteños que antiguamente trabajaban no solo en el agave, sino también en el maíz u otro tipo de cultivo e incluso en cuidado de animales; pero ahora, gracias a la especialización, se dedican a labores bien delimitadas y definidas. Por tal motivo, hoy existen jimadores, cargadores, plantadores, fumigadores, entre otros, que pueden ser contratados por las empresas o particulares de manera continua o estacional, con y sin prestaciones de ley.

La especialización trajo consigo oportunidades laborales para otras personas y por tanto abrió oferta para los jornaleros indígenas provenientes del sureste mexicano, cuya llegada data de 1999, cuando un empresario tequilero alteño propietario de predios en el estado de Chiapas en el sureste mexicano, decidió llevar a varias decenas de jornaleros indígenas a las tierras alteñas para atender la creciente demanda de mano de obra en la agroindustria del tequila. Los jornaleros indígenas no es que hayan desplazado laboralmente a los alteños -que se quedaron con los trabajos mejor remunerados y que exigen cierta especialización y no mucho desgaste físico-, sino que las masivas migraciones indígenas y en el contexto de especialización del mercado de trabajo, generó nichos laborales para el grupo de jornaleros indígenas, 
asignándoles los trabajos con mayor exigencia, desgaste físico e igual o menor retribución y que se consideran de baja estima. El argumento que sustenta este nicho laboral parece ser muy sencillo: la indianidad de los jornaleros migrantes vista en sentido peyorativo.

Entiendo aquí por jornalero aquella persona que trabaja sin una actividad fija, es decir, hace lo que le pide quien lo contrata sin la exigencia de algún tipo de seguridad social o prestación. El cobro ordinariamente es por día de trabajo realizado: un jornal. Esta situación traducida en términos sociológicos refiere a un sujeto cuya condición laboral es precaria, quizá la más precaria del mercado laboral. Como tal, el jornalero es casi por definición migrante debido a su condición de empleado sin garantías laborales mínimas, por lo que se dirige constantemente hacia diversos lugares en los que hay trabajos que requieran de sus servicios temporalmente. Dado que algunos de los migrantes indigenas, sobre los que versa el presente trabajo, se están estableciendo en la región, constatamos una movilización hacia otros sectores productivos, por lo que se deja abierta la posibilidad de analizar algunos casos (empleados en comercios, de fábricas, entre otros), que no son jornaleros propiamente.

La población referida oscila mayoritariamente entre los 20 y 30 años, no obstante existen casos de menores y mayores a este rango de edad cuya ocupación actual es mayoritariamente en las labores del campo, por tanto no están disociadas de las actividades que realizaban en el lugar de origen. En cuanto a las mujeres, la mayoría de ellas viajó para acompañar a su pareja. Algunas laboran a la par como empleadas domésticas, otras, quizá la gran mayoria, reducen sus labores a la esfera de lo privado como amas de casa. (Esta caracterizacióntipología emana directamente de mi experiencia de trabajo de campo).

Para el caso que nos ocupa hay dos consideraciones dignas de ser atendidas al referir la situación de los jornaleros indigenas a partir del caso de Los Altos de Jalisco: en primera instancia, se trata de reconocer la manera en que opera la globalización en sistemas de producción determinados, como en el caso específico del tequila. Es decir, hay que valorar las asimetrias en las regiones dentro de un mismo país, las cuales por un lado expulsan población y por otro reciben, porque buscan mano de obra, normalmente en condiciones de vulnerabilidad y necesidad para laborar. Ello hace posible constatar cómo las migraciones refuerzan las desigualdades suscitadas en la actualidad por un régimen neocolonial comandado por empresas multinacionales que han cambiado la propiedad de la tierra en las regiones 
periféricas y han mecanizado las tareas de la población, provocando un excedente de mano de obra, que se traduce en un proletariado desarraigado y propenso a marcharse de sus comunidades de origen.

En el tenor de lo antes dicho, los jornaleros se vuelven una población susceptible de prácticas y expresiones racistas, porque dicha proletarización se ha efectuado fundamentalmente con poblaciones indígenas. Esto pone a la población indígena jornalera en otro nivel de subordinación, en el que a mi juicio, se combinan y entrecruzan la etnicidad y la clase, por ser indígenas y por ser jornaleros, todo ello en el marco del trabajo agrícola en el que confluyen oferta y demanda, "mediados por contextos sociales y culturales que intervienen para definir su comportamiento" (Lara y de Grammont, 2000, p. 123). Esa mediación social y cultural en el contexto alteño está dada por la etnicidad y el racismo en donde las referencias hacia lo indigena se convierten en un estigma que condiciona sus relaciones laborales y sociales.

Tales dinámicas se enmarcan en un proceso de modernización y de reestructuración productiva (Lara y de Grammont, 2000; Lara, 1998) como se ve concretamente en el caso del tequila, cuya potencialidad para convertirse en un mercado de trabajo (Lara y de Grammont, 2000) depende de la capacidad que las empresas tengan para allegarse de la mano de obra que requieren y gestionarla de acuerdo a sus necesidades, mediante una administración segmentada de la misma. Es decir, en base a diferentes criterios, las empresas dividen el mercado de trabajo entre la mano de obra local por una parte y la mano de obra foránea por otra, valiéndose de diferentes mecanismos de enganche y contratación.

Justo como ocurrió con las primeras incursiones de migrantes provenientes de Chiapas a Los Altos de Jalisco, en donde eran llevados a dicha región por un empresario alteño con los viáticos pagados, así como con la garantía efectiva de un trabajo (es decir migraban ya contratados), un techo para pernoctar y algo de despensa para atenuar el hambre. Los migrantes fueron llevados a laborar bajo condiciones concretas dictadas por las imperiosas necesidades del mercado agroindustrial del tequila, "dado que la población local no era suficiente" (Entrevista a Willy Fonseca, Agosto, 2012).

Con el paso del tiempo y en atención a la subsecuente especialización y diversificación que tuvo la industria del tequila en sus labores, la población local literalmente se apropió de los puestos que requerian mayor destreza, con los argumentos de capacidad, conocimiento y herencia. Siendo así que para los contratistas y empresarios 
locales, la dinámica de selección de mano de obra dependería de las actividades a realizar, las cuales iniciaron siendo diferentes para la población local y para la población indigena migrante.

La demanda de mano de obra en Los Altos de Jalisco iniciada por la agroindustria tequilera, participa de una dinámica conferida por los procesos de restructuración productiva, a su vez mediados por elementos de carácter social y cultural, los cuales según mi perspectiva, generarán, tal como lo dicen Lara y de Grammont, "a través de la flexibilidad laboral, un mercado de trabajo segmentado que refleja las asimetrias de clase, género, étnicas y generacionales" (2000, p.123). A lo cual abono que dichas asimetrías adquieren una fuerza específica de acuerdo al contexto ideológico, histórico y cultural en el cual se suscitan.

Así pues, la migración de estos contingentes de jornaleros implicó para la región de Los Altos de Jalisco una transformación en muchos ámbitos de la vida social, a la par de las de carácter económico y productivo, se desencadenaron una serie de fenómenos que tenían como denominador común la presencia del grupo indígena. Se trataba por tanto ya no solo de un fenómeno que podría ser dimensionado desde la perspectiva de clase, en tanto que intervenian sujetos motivados y regulados aparentemente por cuestiones laborales y de manera consiguiente, económicas, sino también sujetos con características étnicas particulares. Fue justamente dicha combinación entre etnicidad y clase la que en un contexto como el alteño dio pie para que afloraran o se hicieran evidentes prácticas de segregación, discriminación y explotación interpretadas desde la vía del racismo hacia un grupo que, desde el nivel de análisis de clase, se define como jornaleros migrantes, pero que a su vez desde el nivel de la etnicidad, es definido como indígena.

En ese tenor, la etnicidad alude a aquella dimensión de la vida social que hace que todos los miembros de un colectivo sean vistos como pertenecientes al mismo a través de una etiqueta, el caso de los alteños y su contraparte indígena puede ser sin duda uno de ellos. La etnicidad como tal, genera una otredad por medio de una etiqueta social que se manifiesta a través de una serie de rasgos que pueden ser culturales o raciales y que "tienen su origen en fuerzas históricas específicas - estructurales y culturales. No es un rasgo ontológico de la organización humana" (Comaroff y Comaroff, 1992, p. 112). Es una cuestión de clasificación, "la separación y reunión de la población en una serie de categorías definidas en términos de 'nosotros' y 'ellos" (Epstein, 1978, p. 91), que por supuesto no son ajenas a otras dimensiones de la vida social, tales como el género, la raza o la clase. 
Desde el caso en cuestión la etnicidad pone en juego tres elementos: la identidad, la cultura y el poder, todos ampliamente estudiados en la antropología. Al respecto de la identidad es preciso reconocer que esta se crea en las relaciones. En el caso de los alteños podríamos pensar en tres momentos en los cuales, la identidad se ha ido configurando, el primero de ellos, en las relaciones coloniales a través de la formación de una región con claras intenciones de diferenciarse, protegerse de los habitantes originarios de dichas zonas en la fase colonial; un segundo momento tiene que ver con la migración internacional de arandenses, cuyo estilo de vida y cosmovisiones se ven confrontadas por la experiencia del abandono (temporal o definitivo) del terruño a principios del siglo XX; y un tercer momento es el de la migración interna de jornaleros indígenas a la región alteña de Jalisco, que se pone en evidencia en el plano inmediato de la interacción durante la jornada laboral desde finales del siglo XX (notas del Diario de campo 2012).

En ese contexto es pertinente reconocer que dentro de México, uno de los colectivos que más ha padecido negativamente los estragos de la etnicidad, son los pueblos indígenas, los cuales han sido incorporados a un sistema de clasificación heredado del colonialismo en el que se fusiona lo racial y lo étnico y en donde ellos son ubicados por debajo de los mestizos y blancos españoles, quienes supuestamente han preservado su herencia por más de 500 años. Dichas prácticas son por tanto una expresión de la prevalencia de un racismo estructural que impuso una serie de condicionantes para denostar e inferiorizar a dicha población, manteniéndola históricamente en los estratos de menor estima social, con lo cual se logró su posterior exclusión y explotación en su propia tierra.

El racismo estructural a través de la clasificación colonial sentó las bases sociales de la inferioridad indígena hasta nuestros días y se hace presente en prácticas como la explotación, segregación y discriminación. Es decir, no se trata de la petrificación del racismo a través del espacio y el tiempo, sino más bien de su resignificación a partir de los contenidos coloniales en los diferentes acontecimientos históricos sociales. En ese sentido, tales categorias histórica y culturalmente construidas, mas no biológicas, continúan operando con una fuerza política y social en varias partes de México (Stephen, 2007, p. 209), tal es el caso de los jornaleros indígenas en los Altos de Jalisco.

En términos generales esta es la situación de miles de jornaleros y jornaleras indígenas distribuidos a lo largo y ancho del país. Ellos han 
sido clasificados socialmente por el patrón de poder mundial construido a partir de la colonización del continente americano. De esta clasificación se han servido los poderes locales de los lugares en donde coexisten indígenas y no indígenas para percibirlos, posicionarlos y referirlos como naturalmente inferiores. Tal clasificación enunciada tiene uno de los ejes fundamentales en la idea de raza, se trata por tanto de una "construcción mental que expresa la experiencia básica de la dominación colonial y que desde entonces permea las dimensiones más importantes del poder mundial..." (Quijano, 2000, p.1). Por supuesto que dicha situación no es simplemente una pervivencia del pasado, sino que se crea y recrea históricamente, pero manteniendo en términos generales las mismas condiciones de subordinación para los indígenas. Es decir, cambian en forma las prácticas e incluso el argumento, pero de fondo, la condición de subordinación y de estima inferior hacia el indigena es la misma.

En el plano laboral, es decir en el campo agrícola, se dan tensiones que ponen de manifiesto que los contenidos de la identidad alteña se esencializan y buscan un proceso de purificación a raíz de la presencia de los jornaleros indígenas chiapanecos, la cual criolliza-blanquiza las relaciones laborales y sociales. Es decir que rescata la pureza del elemento blanco por parte de la sociedad receptora más que el elemento mestizo y por otro, lado etiqueta a su contraparte indígena como lo contrario, denostando inferioridad, justificando explotación e imposibilitando alianzas en pro de derechos laborales, por ejemplo.

Esta forma de discriminación llega a tal grado que los alteños en Jalisco se niegan a realizar trabajos que son designados como exclusivos para los indigenas, que han sido etiquetados étnicamente bajo la categoría de chiapas $^{5}$ o chiapanecos, dando paso con ello a la formación de un grupo étnico al estilo de Barth, pues emergen como categorías de adscripción e identificación que son utilizadas por los actores y tienen, por tanto, la características de organizar la interacción de individuos (Barth,1976, p. 10), en ese sentido la identidad alteña es la que media y configura las relaciones laborales y sociales con los jornaleros indigenas.

La etiqueta racial chiapas sirve para referirse a una persona que es notoriamente diferente al prototipo alteño antes mencionado: moreno, chaparro, tosco: indio (de nueva cuenta en el sentido peyorativo del término, independientemente del lugar o del grupo étnico de procedencia).

5 Es importante aclarar que no todos los jornaleros provienen de la misma región ni del mismo grupo étnico. Pero en Arandas han sido homogeneizados bajo la categoria de chiapas. 
Esta no solo denota un imaginario o una ideologia, por un lado de dominación y exclusión y por otro de sumisión, subordinación y marginación, sino que se espacializa (Alonso, 1994) en lugares y actividades consideradas como propias de los jornaleros indígenas, manifestando con eso una supuesta inferioridad de indigenas migrantes frente a los trabajadores no indígenas.

Tal categoria ha sido asumida por muchos jornaleros migrantes para identificarse o referir a alguna persona "...mira aquel es un chiapas también..." Alexis, migrante guatemalteco radicado en Los Altos de Jalisco, usa esta expresión para presentarme a otro migrante, quien por cierto tampoco era chiapaneco, pero que en el imaginario alteño son etiquetados y designados de tal manera (Notas del diario de campo 18 de septiembre, 2011). Esta categorización de los sectores de la población alteña en categorias de status exclusivas e imperantes tales como los chiapas y los alteños fungirá como decisiva en todos los niveles de la vida laboral y social, pues es en base a ella y su significado que se construyen, refuerzan y legitiman las desigualdades, pues hay una aceptación del principio de que las normas aplicadas a una categoria pueden ser diferentes de las aplicadas a otra (Barth, 1976, p. 33), siendo las de más prestigio y estima social las del grupo que se encuentra en condiciones más favorables: los alteños.

No se debe perder de vista el hecho complementario de que la identidad que se le imputa a un grupo social desde el exterior puede ser muy diferente de cómo se experimenta esa misma identidad subjetivamente (Comaroff y Comaroff, 1992, p. 120) y que evidencia la heterogeneidad que permea al fenómeno en cuestión. Es necesario aclarar que ni el grupo de los chiapas ni el de los alteños es un todo homogéneo estrictamente definido, en ambos grupos hay tensiones que dan muestra de ello. Sin embargo, para los fines del presente apartado basta con afirmar la multiplicidad de percepciones y autopercepciones en torno a sí mismos, no obstante hay referentes que dan cuenta de por lo menos tres acepciones sobre la manera de asumir su propia identidad que se pondrán en discusión: una que la hace coincidr con la imputación de afuera, otra que crea una distinción entre lo impuesto y lo experimentado subjetivamente y finalmente, otra que se sirve de la categoria identitaria que se le atribuye pero que trata de resignificar sus contenidos.

Es importante poner de manifiesto cómo el grupo alteño define a su contraparte indígena con un sentido pleno de inferioridad y pasividad, en la que incluso se pone en tela de juicio la humanidad 
misma del jornalero migrante. El alteño se mira a sí mismo, hurga en su historia y no encuentra un referente próximo que le ayude a pensar la diferencia, esa diferencia que le remite a un pasado nacional que por mucho parece estar olvidado y no coincidir en la región; visualiza a sus iguales en apariencia física, costumbres, hábitos y valores y dado que no tiene referentes próximos, se sirve del contexto y la historia nacional para definir a ese otro, al indigena.

De un lado, el alteño muy seguramente no sabrá mucho sobre sus orígenes, pero hay algo que en esa definición parece quedarle claro, no hay un antecedente indigena en su región, en su familia, en su contexto. Sus modelos y aspiraciones sobre los cuales configuró su identidad estaban sustentados en modelos construidos en escala ascendente: primero el colono europeo, español y luego el norteamericano, que dotaban a su imagen de elementos para sustentar su blanquitud, entendida como supremacía.

De tales apreciaciones deriva que un colectivo que se supone que es diferente a lo que se supone que es común, sea localizado en el último escalafón de la estima social, garantizando con ello una desigualdad generada por relaciones étnicas, cuya máxima expresión será el racismo, del que hablaremos más adelante. Se sigue entonces que lo étnico se configura como principio rector de las relaciones laborales, generando dos colectivos diferenciados, siendo el de los chiapas perjudicado por la exclusión y la desigualdad, ya que se busca la figura del indígena para marcar la superioridad del alteño, cuestión que se hace evidente en acciones en las que se va a permitir pagar menos por ser indigena.

La etiqueta indígena servirá por tanto para categorizar la vida laboral y social, que en otros casos puede generar o no comunidad, pero sí puede generar una condición, que se hace fehaciente en la estructura organizativa del mercado de trabajo, al grado de que los empleadores locales prefieren, en determinadas circunstancias, a los jornaleros indígenas bajo argumentos racistas que se sustentan en la dinámica étnica entre dichos grupos, pues ellos “...aunque son más guandajos, son más rendidores...” (Entrevista a Pedro González, abril de 2012), "[...] son como burritos de carga..." (Entrevista a Salvador Jiménez, enero de 2012). Dicha preferencia normalmente termina con descontentos, injurias y desprecio hacia los indígenas:

-[...] solo los había contratado para aprovechar el domingo, que la gente de aquí [alteña] trabaja mejor, es más limpia, hace más caso, 
no tienes que andar atrás de ellos todo el rato y que con estos es una lata andar diciendo y diciendo y no entienden.

Su ayudante, 'el feo' corroboró sus palabras diciendo:

-Hijos de la chingada, por más que les decía una cosa ni caso hacian, uno tiene que andar batallando para buscar al jefe de la cuadrilla para que a él sí le hagan caso, porque él sí habla como ellos. (Notas del diario de campo, 18 de septiembre de 2011)

Como lo muestra un apartado de la entrevista, la dimensión étnica se vuelve el criterio que direcciona las relaciones laborales de los jornaleros indígenas y sus empleadores y opera en dos niveles: el primero que se lleva a cabo a través de una valoración positiva, en torno a las destrezas, habilidades, capacidades del grupo indígena, pero que no por ello cambia ni la condición de explotación, ni la de discriminación, sino que se sirve de ellas justamente para allegarse de mano de obra siempre dispuesta a trabajar; y el segundo, la valoración negativa que usa el argumento étnico para justificar el reproche, reclamo, discriminación y explotación a la población indígena utilizando diferentes justificaciones que siempre ponen al indígena como propiciador y por tanto culpable de las reprimendas y la estima negativa que recibe.

Pero también la clase y la etnicidad operan en una escala que podriamos considerar más horizontal, no por el ejercicio de igualdad que pudiera generar, sino por el nivel de relación que propicia en tanto jornaleros, quizá sí podría haber un poco más de igualdad pensada en términos de clase. En el caso de los jornaleros alteños que trabajan en los mismos campos que los indígenas, es constante ver una actitud de recelo hacia los extraños, porque los indígenas trabajan en colectivos familiares claramente diferenciados étnicamente, con lo cual tienen la posibilidad de obtener un ingreso relativamente mayor, pero el recelo es también porque durante el día de trabajo los jornaleros indígenas dan cuenta de su gran capacidad física, casi no descansan. Por lo regular hacen una ingesta rápida de alimentos, lo cual les ofrece la posibilidad de aventajar más las labores, situación que termina beneficiando a los empleadores y no a los compañeros jornaleros, según estimaciones de los últimos.

- Estos son unos perros para esta chamba, en lo que uno hace una arpilla ellos ya llevan tres, nada más se oye al llegar al campo 
la sonata de los tomates en los botes, pa pa pa pa pa, sin parar, casi que ni para tomar agua (Jesús, jornalero alteño, 20 de septiembre de 2011).

El trabajo agroindustrial en Los Altos de Jalisco evidencia un espacio laboral etnizado a dos niveles: el primero es el que tiene que ver con el patrón (propietario o empresario) hacia los jornaleros indígenas y se explica en el sentido de que para los patrones, un jornalero por su procedencia, sus rasgos físicos, sus costumbres y tradiciones es sujeto de explotación "[...]pues así están acostumbrados...".

Me interesa destacar el sentido que doy a la palabra explotación, principalmente la refiero en términos económicos, en los que el trabajador, dígase jornalero, no recibe una compensación suficiente para hacer llevadera su vida y potencializar su desarrollo, así como el de su familia. Pero también y sobre todo, lo uso en el sentido de la interpretación marxista que hace Fromm de la explotación, en la que nos dice que la preocupación de Marx al respecto es "por la liberación del hombre de un tipo de trabajo que destruye su individualidad, que lo transforma en cosa y que lo convierte en esclavo de las cosas" (Fromm, 2005, p. 60). Es decir, hablo de una circunstancia en donde la subsistencia está estrictamente limitada por la variante económica, de tal suerte que si no se posee un ingreso monetario es sumamente difícil salir avante, por lo que la venta de mano de obra, muchas veces al precio que sea se convierte en la única alternativa para los jornaleros indígenas.

Por otro lado, en un segundo nivel se encuentran las relaciones entre jornaleros alteños y jornaleros indígenas, que se hace palpable en recelos y conspiraciones, para que los patrones ya no los contraten, e incluso en alianzas para quitarles trabajo a los jornaleros indigenas. Es común escuchar apelaciones que tienen que ver con la herencia casi ancestral de las labores que se realizan, por parte de los jornaleros alteños, lo cual sirve como sustento para afirmar su superioridad, no solo en la destreza para efectuar las tareas sino también a nivel cultural. Es por ello que ante la menor situación se echa en cara la supuesta inferioridad del indígena, la cual se hace evidente aparentemente en las formas en que se refieren a sus hijos, al vestido que portan y a las condiciones del mismo, a la manera en que hablan, a lo poco que descansan y a los errores que cometen durante la jornada. 
- [La situación está] bien para los patrones, pues les hacen la chamba bien rápido, pero a nosotros para nada, porque nos estaban quitando trabajo.

- ¿Cómo es eso?

- [Pues como ellos] trabajan a toda máquina, los patrones los están prefiriendo para ciertas cosas, entre ellas el tomate; pero que también influye el hecho de que la gente de Arandas ya no quiere hacer esos trabajos por esos salarios. Quién sabe qué pasa con la gente, ya se hizo muy delicada, ya no quieren trabajar, por eso los patrones pues aprovechan que viene gente de fuera y como tienen necesidad pues de eso se valen. Aquí es como el norte para ellos sin necesidad de salir del país, como hace la gente de Arandas. (Jesús, jornalero alteño, 20 de septiembre de 2011)

Valga la precisión de que la situación antes mencionada opera de la misma manera en los diferentes productos agrícolas que se cosechan en la región (agave, tomate, maíz) hacia los diferentes grupos de jornaleros indigenas (tzeltales, choles, tzotziles, tlapanecos, mixtecos); es decir, aunque sean diferentes grupos étnicos, diferentes migraciones y ocupaciones, son unificados en la discriminación, el maltrato y la no-integración social.

En el nivel de las relaciones entre jornaleros existe una diferencia sustancial entre jornaleros de diferentes grupos étnicos, sin embargo dichas divisiones no son excluyentes pero tampoco incluyentes, sino que rayan en una mera división que no es conflictiva (como recurrentemente lo es entre alteños e indígenas), establecida primero por la lengua, luego por el lugar de origen y finalmente por las costumbres, de tal suerte que es común ver en los campos agrícolas alteños cómo los grupos familiares de tlapanecos trabajan en conjunto, sin interactuar con los Mixtecos de Oaxaca, los Otomíes o Purépechas de Michoacán, o los Tzeltales de Chiapas. A diferencia de lo que pasa con los jornaleros indígenas en Estados Unidos, donde al parecer la procedencia geográfica tiende a generar alianzas que decantan algunas veces en movimientos organizados con fines diversos (Revilla, 2007; Fox, 2005; Delgado, Márquez y Rodríguez, 2004).

Las categorias étnicas al interior de un solo grupo no se presentan de manera homogénea, evidencia de ello es el caso de jornaleros indígenas que fungen como intermediarios en su mismo grupo, siendo 
ellos quienes posibilitan o impiden el acceso al trabajo a sus compañeros. Los intermediarios llevan un porcentaje del pago total por la faena diaria, así que primero hacen sus cálculos separando sus ganancias por lograr el contrato del trabajo y luego obtienen lo que durante el día logren recabar con su trabajo.

Los intermediarios son ordinariamente aquellos que conocen y saben moverse en los intersticios de la vida laboral e incluso social del municipio pues tienen más tiempo visitando o de plano radicando en el mismo. Han desarrollado también mayor destreza para las labores agrícolas y los negocios, hablan con mayor fluidez el castellano, pero conocen a cabalidad la lengua de su grupo, lo cual les hace posible intermediar en confusiones lingüisticas, lograr acuerdos sin que los alteños se enteren o solucionar conflictos. Los intermediarios aprovechan estas situaciones para reproducir la lógica de la opresión y explotación de la que originariamente fueron y siguen siendo sujetos, tal como lo expresó en su momento Freire (2005) al hacer notar que cuando alguien que ha sido oprimido tiene la oportunidad de superar la opresión e incluso accede a algún mecanismo de poder, este tiende a transformarse en opresor.

Hay empresarios que se han percatado de que existe entre los mismos jornaleros chiapanecos la presencia de intermediarios o coyotes, que aprovechan varias de sus ventajas en relación con sus compañeros, como por ejemplo: un mejor dominio del castellano, mayor tiempo residiendo en los Altos de Jalisco y mayor destreza para las labores agrícolas tequileras. Es así que algunos coyotes chiapanecos, acorde a su cargo, reciben los salarios de sus cuadrillas, situación que les permite auto-atribuirse una cuota que puede llegar a representar hasta $10 \%$ del salario de cada jornalero y aunque es un arreglo pactado entre el migrante y el coyote, el salario final del migrante se ve disminuido.

Así pues, algunos jornaleros indígenas son doblemente explotados: por el empleador que paga un salario por jornada laboral y por el coyote o intermediario que se queda con una parte del salario del migrante. En este proceso la mano de obra del migrante resulta clave en la acumulación de capital, donde la discriminación y el racismo funcionan como mecanismo que permite pagar bajos salarios e incluso no pagarlos.

[...] El otro día un patrón nos llevó a Jesús María, solo a mí y a Antonio, nos fuimos con él. Le hicimos cinco arpillas y cuando 
acabamos y le dijimos que nos pagara nos dijo: váyanse a la verga, no les voy a pagar y nos corrió a patadas. Así que ya ni nos regresó, nos tuvimos que venir caminando porque no teníamos dinero, en la carretera pedimos que nos trajeran, pero hicimos 4 horas hasta la casa, llegamos como a las 10 o 11 pm [...] (Cipriano, adolescente indigena, noviembre de 2011)

En el caso específico del campo social gestado por la agroindustria tequilera hablamos de un sistema e imaginario social más amplio, la sociedad jalisciense que inventa y describe al chiapaneco como su inverso, un ser inferior (inferioridad congénita), objeto del escarnio y del desprecio, desde donde constata una supuesta superioridad, que legitima a su vez la explotación del chiapaneco. Se vuelve pertinente precisar entonces que el racismo es una expresión de clase y de poder que se filtra en los mercados laborales y sirve de mecanismo de explotación, por supuesto de clase, que tiene su cruce en la variante étnica y posibilita el surgimiento del racismo enmarcado en el espacio laboral de una agroindustria enclavada a su vez, en el mercado global, que toma de la constatación de las diferencias fenotípicas, culturales y de la desprotección social, laboral y estatal en general, sus herramientas más socarronas para discriminar, segregar, excluir y explotar al migrante.

La indianización laboral o racialización del trabajo no solo se permite pagar menos sueldos, sino que además, da la pauta para desvalorizar la fuerza de trabajo a sabiendas de que ante cualquier circunstancia los jornaleros pueden ser desplazados o sustituidos por otros con igual necesidad de trabajo y lo más crítico, quien se encuentra en una posición más ventajosa en cuanto a clase se refiere, se da la potestad de naturalizar la desigualdad y la violencia que ejerce. Se deduce así de sus conductas, que el problema es justamente el de la indianidad de sus empleados o de la gente a su cargo y que él no tiene nada de culpa por la violencia y discriminación que genera. Alli no hay un ejercicio autocrítico, pero tampoco lo hay de parte de autoridad alguna, lo cual responde a una lógica muy puntual.

La etnicidad se convirtió en un factor a favor de la maduración de un orden capitalista colonial y postcolonial caracterizado por marcadas asimetrías que siguió proporcionando una base cultural y organizacional para una división del trabajo muy estratificada; racionalizó la posibilidad de ascenso social y un rasgo distintivo, carácter - ethos de éxito (Comaroff y Comaroff, 1992, p.130). Esto posibilitó además la desigual distribución de poder material, político y social en virtud de la pertenencia a un grupo. 
Por tanto, el fenómeno de migraciones de jornaleros indígenas en Los Altos de Jalisco y su incorporación en un contexto de desigualdad al mercado laboral alteño, pone en evidencia la carga ideológica de una región cuya identidad está en estrecha conexión con los elementos de una identidad nacional, supuestamente homogénea y a la cual se supone se debe aspirar. Es además, una identidad que históricamente ha sido considerada en la escala superior de valoración: el blanco, criollo, católico. Mientras que en el plano inferior, los sujetos históricos de la desigualdad han sido los indígenas.

Estas consideraciones son las que llevan a plantear la pertinencia de repensar el racismo hacia las poblaciones indígenas. Considero que es esta la directriz que, desde el caso de estudio, hace posible no solo la comprensión de las relaciones laborales y sociales de los jornaleros agrícolas, sino también la propensión de estos a marcharse de sus lugares de origen por la falta de condiciones; siendo considerados como mano de obra barata en los lugares de destino, pero una mano de obra que va a ser explotada, no por la obtención de plusvalía, sino porque históricamente ha sido construida como objeto degradado y por tanto, a través del trato que recibe se pone en cuestión y se degrada la humanidad misma de jornalero (Macip, 2007). Todo esto se da bajo el argumento de que así ha sido siempre y así están acostumbrados, "siendo lo indio una categoría auto-explicativa producida en el estatus liminal en que los trabajadores viven..." (Macip, 2007, p. 49) antes, durante y después de su actividad como jornaleros.

Visto desde esta óptica, el racismo pone de manifiesto los diferentes niveles en que se entrecruzan las desigualdades en el mercado de trabajo. Primero porque los jornaleros indígenas han sido históricamente condicionados por los legados coloniales que se han resignificado a través del tiempo en el acceso a oportunidades; con lo cual, el vínculo que tenían en sus tierras a nivel de sustento, poco a poco se ha venido degradando, al grado de verse impelidos a salir de sus comunidades ofertando su fuerza de trabajo al mercado capitalista para poder sobrevivir. Segundo, porque dentro, pero sobre todo saliendo de sus comunidades, se topan con una estructura social que los posiciona de manera natural en los niveles inferiores.

Tercero, porque una vez lograda la venta de su fuerza de trabajo, el salario que reciben es inferior, o si no lo es, el trabajo efectuado es el que goza de poca estima, lo cual pone de manifiesto una lógica de superioridad de parte de quien contrata. Es decir que no solo se pagan salarios para mantener enganchada la fuerza de trabajo, sino 
que se pagan así porque por ser indígenas no merecen más, "con ellos los acuerdos son otros", "así están acostumbrados a trabajar y a vivir con poco" (Trabajo de Campo, Arandas, 2012). En ese sentido, el trabajo se racializa para poder llevarse a cabo y justificar la explotación y discriminación.

Cuarto, a nivel de las relaciones entre los pares de clase, es decir, con los jornaleros alteños, la dimensión étnica guarda primacía manifestándose en dos niveles: uno que tiene que ver con el posicionamiento en positivo, que permite el reconocimiento de habilidades y destrezas para el trabajo y otra en sentido negativo, que por el hecho de ser considerado como indígena, limita el establecimiento de relaciones sociales, alianzas en pro de sus derechos e igualdad de trato.

\section{Consideraciones finales}

Con el arribo de los jornaleros chiapanecos a tierras alteñas en Jalisco se han suscitado relaciones laborales y sociales mediadas por el factor de clase y etnicidad que aquí se han interpretado como formas de racismo hacia la población jornalera, situación que además da pie para repensar el posicionamiento indígena en el imaginario nacional de la actualidad, en el contexto de globalización, de manera muy puntual en los mercados de trabajo, para este caso el agrícola.

Ante la presencia de jornaleros en la región de Los Altos de Jalisco han aflorado elementos constitutivos y delimitadores, que como se dijo antes, se poseían pasivamente en lo que se considera como la identidad alteña (acendrado catolicismo, predominante fenotipo europeo o caucásico, producto de la pervivencia colonizadora española; una tradición migratoria a Estados Unidos; de espíritu individualista; especializada tanto en la producción de tequila, como de lácteos, ganadería vacuna y productos avícolas), pero también se han identificado a los otros y se les han atribuido características que sirven para segregarlos, marginarlos y explotarlos. Por tal motivo, el análisis de la etnicidad a partir de la narrativa en torno a la formación de la región alteña ha sido primordial para mostrar los discursos y prácticas en las que se sustentan las desigualdades en el mercado de trabajo, que como se vio, se viven de manera íntima y por tanto dan lugar a comportamientos naturalizados que coexisten de manera inconsciente pero que se materializan en la interacción cotidiana. 
El desplazamiento indígena de sus tierras para laborar en agroindustrias y agronegocios hace evidente la manera en que dichos grupos pasan a conformar el engranaje fundamental de las empresas, tanto nacionales como multinacionales, que se benefician de la precariedad del campo y de la alienación de las tierras a los indígenas, lo que se traduce en cambios indelebles en su cultura y principios (Restrepo, 2009, p. 226).

Frente al jornalero indígena migrante y sus prácticas culturales y sociales, resalta la necesidad de identificarse de una determinada manera: honrados, francos, trabajadores-emprendedores, devotos y blancos, marcando justamente el limite ante una manera otra de concebirse que quizá pueda alterar el orden social y cultural establecido. En la actualidad, ese otro ha llegado a tierras arandenses, está ahí, mas no en la forma esperada, siendo por tanto una especie de aberración a los prototipos anhelados por los alteños. Es un otro que ciertamente rememora parte de un pasado nacional pero que, no obstante, no tiene cabida en la historia enseñada en la región. Por tanto, la migración indígena propicia que los alteños de Jalisco reafirmen su identidad colectiva para crear una especie de barrera frente a lo que se presenta como ajeno.

Dichas prácticas se han interpretado desde la tónica de la prevalencia de un racismo estructural, que se nutre de la clasificación social impuesta en el continente americano durante la colonia (Quijano, 2000). Este impuso una serie de condicionantes a la población indígena que hasta nuestros días la sigue posicionando en subordinación e inferioridad. El racismo se vuelve funcional al sistema porque permite la reproducción del mismo, una base de mano de obra subordinada e inferior, siempre dispuesta a formar parte del mismo a través de la venta de su fuerza de trabajo. El sistema crea en los indígenas un ejército industrial de reserva, fuerza de trabajo siempre disponible, cuyas necesidades de subsistencia limitan tan siquiera la visualización de mejores condiciones.

El racismo también es funcional para una sociedad que ha crecido con el imaginario y aspiraciones puestos en los modelos civilizatorios blancos, mestizos o no indígenas. Las condiciones históricas en el plano económico, político, religioso, cultural se asientan con base en ese modelo. La desigualdad se naturalizó, la dicotomía pasó a ser normal, ricos y pobres, blancos e indígenas, o más precisamente indígenas y no indígenas. El racismo da sustento para afirmar la que se piensa es la supremacía de un grupo, para reafirmarse por oposición. 
Pero el racismo también evidencia la degradación humana y social que se ha venido construyendo a lo largo de los siglos. La lógica de acumulación ha hecho que se pierdan de vista los fundamentos de la humanidad, el olvido de una ética humana como fundamento de respeto a la humanidad misma, hombres y mujeres. No se trata de culpar al sistema de todo lo que acontece porque entonces, como humanos nos reduciríamos a sujetos pasivos de su acción, seres inertes. No podemos obviar la responsabilidad humana, colectiva e individual, pero tampoco debemos perderla de vista, ni darle su justa dimensión a la influencia del mismo sistema, en el sentido de obviar cómo ha incrementado y acelerado la formas de desigualdad.

\section{Referencias}

Alonso, A. M. (1994). Políticas de espacio, tiempo y sustancia: formación del Estado, nacionalismo y etnicidad. En Camus. M. Las ideas detrás de la etnicidad. Una selección de textos para el debate (pp.159-183). Antigua Guatemala: CIRMA.

Barth, F. (1976). Los grupos étnicos y sus fronteras. México: Fondo de Cultura Económica.

Carrillo, R. y Salgado, S. (2002). Racismo y vida cotidiana. En una ciudad de la sierra Ecuatoriana. Ecuador: Ediciones Abya-Yala.

Comaroff, J. y Comaroff, J. (1992). Theory, ethnography, historiography. San Francisco, Oxford: Westview Press, Boulder.

Delgado, M. C. (2007). Una imposible vuelta a casa. Identidades nómadas y múltiples. México, UACM.

Delgado, W. R., Márquez C. H. y Rodríguez R. H. (2004, julio-diciembre). Organizaciones transnacionales de migrantes y desarrollo regional en Zacatecas. Migraciones Internacionales, 2 (4), 159-181.

Durand, J. (2007). El programa bracero (1942-1964). Un balance crítico. Migración y desarrollo, (9), 27-43.

Epstein, E. P. (1978). Ethos and identity. Three Studies in ethnicity. London: Tavistock Publications.

Fábregas, A. (1986). La formación histórica de una región: Los Altos de Jalisco. México: Centro de Investigaciones y Estudios Superiores en Antropología Social.

Fox, J. (2005). Repensar lo rural ante la globalización: la sociedad civil migrante. Migración y Desarrollo, (5), 35-58.

Freire, P. (2005). Pedagogía del Oprimido. México: Siglo XXI. 
Fromm, E. (2005). Marx y su concepto del hombre. México: Fondo de Cultura Económica.

Gilabert J. C. y Camarena L. M. (2004). El alteño global. Trayectorias evolutivas de los altos de Jalisco: evolución politica y sociocultural en la era de la sociedad global. México: Universidad de Guadalajara y Colegio de Jalisco.

Hernández. R. (2012). Notas del diario de campo 2011-2012. México: Inédito.

Hernández. J. J. (2004). Las vinazas del tequila. Nuevos usos, viejas prácticas en el tratamiento de las aguas residuales del tequila en Los Altos de Jalisco. Ponencia presentada en el III Encuentro de investigadores de la cuenca LermaChapala-Santiago. Chapala, Jalisco (inédito).

Hernández. J. J. (2005). El agave tequilero ¿Una hortaliza? Ponencia presentada en el V Congreso Internacional de la Red de Investigación Socioeconómica en Hortalizas, Frutas y Flores (RISHORT). Tijuana y Mexicali, B.C. (Inédito).

Lara, S. (1998). Nuevas experiencias productivas y nuevas formas de organización flexible del trabajo en la agricultura mexicana. México: Procuraduría AgrariaJuan Pablos.

Lara, S. y de Grammont, H. (2000). Nuevos enfoques para el estudio del mercado de trabajo rural en México. Cuadernos Agrarios A.C. Nueva época, (19-20), 122-140.

López, E. (1999). Último cielo en la cruz. México: Universidad de Guadalajara y Colegio de Jalisco.

Macip, R. F. (2007). Racismo y superexplotación: los jornaleros indígenas en el ejército industrial de reserva. Bajo el volcán, 7 (11), 45-60.

Quijano, A. (2000, summer/fall). Colonialidad del poder y clasificación social. Journal of World-Systems Research, XI (2), 342-386.

Restrepo, J. (2009, julio-diciembre.). Reseña Transborder Lives: Indigenous Oaxacans in Mexico, California, and Oregon. Revista Migraciones Internacionales, 5 (2), 223-226.

Revilla, L. U. (2007). La migración transnacional de Oaxaca y Tlaxcala: las organizaciones de migrantes en Estados Unidos. La Paz, Bolivia: Fondo para el Desarrollo de los Pueblos Indígenas de América Latina y El Caribe.

Stephen, L. (2007). Transborder lives. Indigenous Oaxacans in Mexico, California and Oregon. Durham y Londres: Duke University Press. 